\title{
PENERAPAN SISTEM INFORMASI BANK PADA PT. BANK CENTRAL ASIA Tbk (BCA)
}

\author{
Gyanriscky Rigawan, Afriyeni \\ Akademi Keuangan dan Perbankan Padang \\ Afriyeni.yen@gmail.com
}

\begin{abstract}
ABSTRAK
Teknologi merupakan pengaruh penting bagi kemajuan sistem informasi suatu perusahaan. Hal ini tidak terlepas dengan semakin tajamnya persaingan antar perusahaan perbankan, maka dari itu perusahaan perlu menerapkan suatu teknologi sistem informasi pada bank. Sistem informasi pada perbankan bertujuan untuk memberikan kenyamanan, kemudahan dan kepuasan terhadap konsumen atau nasabahnya dan juga untuk perusahaan teknologi sistem informasi yang modern mampu meningkatkan operasional perusahaan. Tujuan penelitian ini adalah untuk mengetahui tentang sistem informasi bank pada PT. Bank Central Asia Tbk (BCA). Teknik pembahasan yang digunakan adalah dengan metode deskriptif. Teknik pengumpulan data dilakukan ke perpustakaan beberapa buku-buku ilmiah dan tulisan-tulisan yang berhubungan dengan pembahasan yang dilakukan serta jurnal yang berhubungan dengan tugas akhir ini. Sistem informasi bank yang ada di BCA yaitu internet banking atau yang dikenal sebagai e-Banking. Istilah e-Banking ini adalah melakukan transaksi, pembayaran, dan transaksi lainnya melalui internet dengan website milik bank yang dilengkapi dengan sistem keamanan. Kelebihan dari eBanking ini adalah nasabah tidak perlu antri untuk melakukan transaksi keuangan. Nasabah bisa langsung melakukan kegiatan perbankan dirumah dan dimana saja. Selain itu juga menghemat waktu, nasabah tidak perlu menghabiskan waktu seharian hanya untuk menyelesaikan berbagai transaksi keuangan. Namun kekurangan dari sistem informasi bank ini adalah rawan pembobolan, ini menjadi perhatian banyak pihak kalau dana nasabah sering dibobol orang tak dikenal. Dana yang hilang sering tidak dapat dikembalikan dan nasabah mengalami kerugian. Selain itu kekurangan lainnya yaitu tergantung pada internet, tidak mungkin melakukan transaksi e-Banking dikawasan yang jaringan internetnya belum ada. Jaringan internet yang diharapkan juga harus lebih kencang kecepatannya, jika jaringan internetnya lama maka e-Banking akan mengalami gagal transaksi.
\end{abstract}

Kata Kunci: Sistem Informasi Bank

\section{LATAR BELAKANG}

Keberhasilan bank akan sangat ditentukan kualitas kinerja teknologi sistem informasinya, yang akan terus dikembangkan secara luas untuk memenuhi kepentingan bisnis bank dan nasabahnya. Kecenderungan proses otomatisasi ini akan terus berlanjut di tahun-tahun mendatang, seiring dengan perkembangan perbankan nasional sebagai lembaga kepercayaan masyarakat dalam menjalankan fungsi sebagai perantara keuangan (financial intermediary). 
Di dalam persaingan yang sangat ketat, untuk menjaga loyalitas nasabah bank harus mempunyai ide atau inovasi terbaru agar bisa menjaga kualitas dan pelayanan bank. Karena kepuasan nasabah juga menjadi salah satu tujuan bank supaya bank tersebut mempunyai nilai pandang yang bagus dimata masyarakat luas. Agar itu semua bisa tercapai, bank harus mempunyai teknologi sistem informasi yang canggih dan mengikuti perkembangan zaman.

Pada dunia perbankan, perkembangan teknologi informasi membuat para perusahaan mengubah strategi bisnis dengan menempatkan teknologi sebagai unsur utama dalam proses inovasi produk dan jasa. Seperti halnya pelayanan electronic transaction (e-Banking) melalui ATM (Automatic Teller Machine), phone banking dan internet banking misalnya, merupakan bentuk-bentuk baru dari pelayanan transaksi manual menjadi pelayanan transaksi yang berdasarkan teknologi.

Hampir seluruh perbankan Indonesia sekarang ini telah memberikan pelayanan secara online dalam bertransaksi. Semakin berkembang dan kompleksnya fasilitas yang diterapkan perbankan untuk memudahkan pelayanan, itu berarti semakin beragam teknologi yang dimiliki suatu bank. Tidak dapat dipungkiri, dalam setiap bidang termasuk perbankan penerapan teknologi bertujuan selain untuk memudahkan operasional intern perusahaan, juga bertujuan untuk semakin memudahkan pelayanan terhadap customers.

Untuk menyaingi pesaing didunia perbankan, salah satu bank yang mempunyai fasilitas ini adalah PT. Bank Central Asia (BCA). PT. Bank Central Asia adalah salah satu bank swasta yang baru menggunakan teknologi informasi sekitar tahun 1989 dengan tujuan untuk membedakan pelayanan dengan bank lain. Dengan menggunakan sistem informasi, BCA mampu menghubungkan antar cabangnya secara online. Produk BCA yang selama ini memanfaatkan teknologi informasi meliputi telegraphic transfer, mail transfer,Automatic Teller Machine (ATM) dan phone banking.

Selain itu bank BCA juga merupakan bank yang menggunakan teknologi informasi terbanyak dan tercanggih. Sebuah bank akan sulit bersaing apabila belum mengadopsi penggunaan teknologi informasi dan sistem informasi dalam menjalankan bidang usahanya karena dewasa ini kebutuhan akan pelayanan perbankan yang cepat, akurat dan efisien sangat dibutuhkan.

Dalam penelitian ini yang akan dibahas adalah bagaimana penerapan sistem informasi bank pada PT. Bank Central Asia Tbk (BCA) untuk meningkatkan pelayanan bank terhadap nasabah.

\section{LANDASAN TEORI}

\section{Pengertian Sistem Informasi Bank}

Sistem informasi bank adalah suatu sistem pengolahan data keuangan dan pelayanan jasa perbankan secara elektronis dengan menggunakan sarana komputer, telekomunikasi dan sarana elektronis lainnya. Penggunaan sistem informasi bank adalah untuk meningkatkan efektivitas dan efisiensi dalam pelaksanaan tugas dan pelayanan kepada masyarakat.

\section{Penerapan Sistem Informasi Perbankan}

Penerapan sistem informasi perbankan mencakup: 
1. Pengawasan aktif dewan komisaris dan direksi

2. Kecukupan kebijakan dan prosedur penggunaan teknologi informasi

3. Kecukupan proses identifikasi, pengukuran, pemantauan dan pengendalian resiko penggunaan teknologi informasi

4. Sistem pengendalian intern atas penggunaan teknologi informasi

Penerapan sistem informasi tersebut dilakukan juga terhadap jaringan yang digunakan untuk mendukung sistem atau aplikasi teknologi informasi. Umumnya jaringan yang digunakan adalah sebagai berikut:

a. Internet

Merupakan jaringan media informasi global untuk umum dan berkecepatan tinggi, yang menghubungkan setiap PC dengan PC lain melalui modern.

b. Extranet

Jaringan komunikasi yang dibangun dari satu perusahaan ke perusahaan ke perusahaan lainnya untuk saling bertukar informasi, bertransaksi dari dan ke supplier, pelanggan dan pelaku bisnisnya.

c. World Wide Web (WWW)

Entitas paling cepat tumbuh dalam fasilitas internet,yang menyediakan fasilitas dan kemudahan dalam membuka atau mengirim informasi melalui saluran/links "hypertext". Dengan entitas ini memudahkan setiap komputer yang terhubung ke web secara tepat mendapat akses informasi umum, walaupun jumlah informasinya banyak atau dari tempat yang jauh.

\section{Perkembangan Sistem Informasi Perbankan}

Seiring dengan perkembangan zaman dan kemajuan teknolgi, berdampak pula pada dunia transaksi perbankan. Saat ini perbankan sudah mulai menggunakan sistem informasi berbasis komputer. Hal ini dilakukan dengan tujuan mempermudah transaksi dengan para nasabah.

Awalnya transaksi bisa dilakukan dengan cara melayani nasabah bertemu secara langsung ataupun nasabah datang kecabang-cabang. Namun sekarang sudah lebih mudah, sebab bank mulai menggunakan sistem informasi berbasis komputer, bahkan sudah bisa mengakses melalui internet baik dengan mobile atau sms sudah banyak diterapkan oleh bank-bank yang ada.

Dalam dunia perbankan, perkembangan sistem informasi membuat para perusahaan mengubah strategi bisnis dengan menempatkan teknologi sebagai unsur utama dalam proses inovasi produk dan jasa seperti: adanya transaksi berupa transfer uang via mobile maupun via teller, adanya ATM pengambilan uang secara cash 24 jam, penggunaan database di bank-bank, sinkronisasi datadata pada kantor cabang dengan kantor pusat.

\section{Peranan Sistem Informasi Dalam Keuangan dan Perbankan}

Saat ini telah banyak para pelaku ekonomi, khususnya di kota-kota besar yang tidak lagi menggunakan uang tunai dalam transaksi pembayarannya, tetapi telah memanfaatkan layanan perbankan modern. Layanan perbankan modern yang hanya ada di kota-kota besar ini dapat dimaklumi karena pertumbuhan ekonomi saat ini yang masih terpusat dikota besar saja. Sehingga sektor perbankan pun agak lamban dalam ekspansinya ke daerah-daerah. Hal ini sedikit banyak disebabkan oleh infrastruktur saat ini. 
Untuk menunjang keberhasilan operasional sebuah lembaga keuangan/perbankan seperti bank, sudah pasti diperlukan sistem informasi yang handal yang dapat diakses dengan mudah oleh nasabahnya, yang pada akhirnya akan bergantung pada teknologi informasi online.Pengembangan teknologi dan infrastruktur telematika di Indonesia akan sangat membantu pengembangan industri sektor keuangan ini, seperti perluasan cakupan usaha dengan membuka cabang-cabang di daerah, serta pertukaran informasi antara sesama lembaga keuangan. Institusi perbankan dan keuangan telah dipengaruhi dengan kuat oleh pengembangan produk dalam teknologi informasi, bahkan mereka tidak dapat beroperasi lagi tanpa adanya teknologi informasi tersebut. Sektor ini memerlukan pengembangan produk dalam teknologi informasi untuk memberikan jasa-jasa mereka kepada pelanggan mereka.

\section{METODE PENELITIAN}

Dalam pengumpulan data dan bahan untuk melakukan penelitian ini, digunakan metode-metode pengumpulan data sebagai berikut:

\section{Metode Pengumpulan Data}

\section{Studi Pustaka (Library Research)}

Penelitian yang dilakukan ke perpustakaan beberapa buku-buku ilmiah dan tulisan-tulisan yang berhubungan dengan pembahasan yang dilakukan serta jurnal yang berhubungan dengan masalah.

2. Studi Lapangan (Field Research)

Penelitian yang langsung objek penelitian di pilih untuk meneliti hasil data sekunder yang diperoleh dari website Bank Indonesia dan tulisan-tulisan yang berhubungan dengan pembahasan yang dilakukan.

\section{Metode Analisis Data}

Dalam menganalisa data, penulis menggunakan analisis data Kualitatif sebagai metode penelitian yang menjelaskan secara Deskriptif yaitu memberikan gambaran tentang penerapan sistem informasi bank pada PT. Bank Central Asia Tbk (BCA).

\section{PEMBAHASAN}

\section{Produk BCA}

Bank Central Asia atau BCA merupakan sebuah bank terbesar di Indonesia, yang melayani seluruh nasabahnya dengan segala kelebihan yang diberikan. Hingga kini kualitas produk dan layanan BCA terus ditingkatkan agar nasabah bisa lebih mudah menggunakannya. Berbagai produk dan layanan telah disediakan oleh pihak bank yang sudah dirancang khusus untuk memenuhi kebutuhan para nasabah secara optimal. Berikut ini adalah beberapa produk dari BCA:

\section{a) Produk Simpanan}

Produk Simpanan merupakan salah satu produk pertama BCA, banyak pilihan produk simpanan yang memberikan kemudahan serta kenyamanan yang sesuai dengan kebutuhan transaksi nasabah, diantaranya: Tahapan, Tahapan Gold, Tahapan Xpresi, Tapres, TabunganKu, Giro, Deposito Berjangka, dan BCA Dollar. 


\section{b) Kartu Kredit}

Selain itu terdapat beberapa pilihan kartu kredit yang disediakan dengan berbagai kemudahan, dan keuntungan, serta kenyamanan yang sudah disesuaikan dengan kebutuhan nasabah seperti: BCA Card, BCA MasterCard, dan BCA Visa.

c) Fasilitas Kredit

Fasilitas ini adalah salah satu kemudahan yang diberikan oleh BCA kepada nasabahnya, banyak manfaat dan fasilitas kredit yang ditawarkan beserta kemudahan dan keuntungan. Diantaranya: Kredit Pemilikan Rumah, Kredit Kendaraan Bermotor, Kredit Modal Kerja, Kredit Sindikasi, Kredit Ekspor, Kredit Investasi, Distrubutor Financing, SupplierFinancing, Dealer Financing, Warehouse Financing, Trust Receipt.

\section{d) Layanan Transaksi Perbankan}

Berbagai fasilitas layanan yang digunakan sebagai pendukung dalam bertransaksi, dengan menawarkan sistem yang aman, mudah dan cepat seperti: Auto Debit, Safe Deposit Box, Transfer, Remittance, Bank Notes, Collection dan Clearing, Traveller's Cheque, BCA Virtual Account, Open Payment, Payroll Services.

\section{e) Layanan Cash Management}

Dapatkan kemudahan dan kenyamanan dalam bertransaksi yang disediakan oleh pihak perbankan dalam serangkaian layanan pembayaran terbaik diBCA seperti: Payable Management/Disbursement, Receivable Management/Collection, dan Liquidity Management.

\section{f) Fasilitas Ekspor/Impor}

Berbagai fasilitas dalam melayani transaksi ekspor dan impor yang ditawarkan di BCA dan nasabah bisa menikmati karena pihak BCA sudah bekerjasama dengan bank koresponden yang tersebar lebih kurang 107 negara, layanan yang diberikan bank BCA adalah sebagai berikut:Letter of Credit (L/C), Negotiation,Bankers Acceptance, Bills Discounting, dan Documentary Collections.

\section{g) Fasilitas Valuta Asing}

Memberikan perlindungan kepada nasabah yang sedang melakukan transaksi internasional tanpa harus takut akan resiko kerugian akibat fluktuasi nilai tukar diantaranya:Spot, Forward, danSwap.

\section{Perbankan Elektronik BCA}

Dengan perkembangan teknologi informasi saat ini, telah mencipatakan jenis-jenis dan peluang-peluang bisnis yang baru dimana transaksi bisnis semakin banyak dilakukan secara elektronika. Sehubungan dengan perkembangan teknologi informasi tersebut memungkinkan setiap bank dengan mudah melakukan transaksi antar bank ke bank dan bank ke nasabah. Perkembangan internet memang cepat dan memberi pengaruh signifikan dalam segala aspek kehidupan kita.

Penggunaan internet tidak hanya terbatas pada pemanfaatan informasi yang dapat di akses melalui media, melainkan juga dapat di gunakan sebagai sarana untuk melakukan transaksi perbankan. Bank BCA mulai memasuki dunia maya yaitu internet banking atau yang lebih di kenal dengan e-Banking, yang merupakan bentuk layanan perbankan secara elektronik melalui media internet. $e$ - 
Banking pada BCA dasarnya merupakan suatu kontak transaksi perbankan antara pihak bank dan nasabah dengan menggunakan media internet.

Banyaknya layanan perbankan elektronik yang disediakan BCA dalam mempermudah para nasabah saat melakukan transaksi perbankan secara cepat, mudah, dan aman seperti:

\section{a) ATM BCA}

ATM BCA kini semakin efisien. Untuk memudahkan nasabah dalam melakukan transaksi perbankan dan untuk menghindari antrian panjang, sekarang terdapat beberapa jenis ATM BCA diantaranya:ATM BCA Multifungsi, ATM BCA Tarik Tunai, ATM BCA Non-Tunai, dan ATM BCA Setoran Tunai/Cash Deposit Machine.

\section{b) Debit BCA}

Lewat kartu papor BCA, BCA menawarkn suatu bentuk kenyamanan dan kemudahan hidup bagi nasabah Tabungan Tahapan BCA, Tapres, dan giro rupiah perorangan. Selain berfungsi sebagai kartu ATM BCA, kartu Paspor BCA dapat digunakan sebagai kartu debit untuk transaksi pembayaran pada saat berbelanja tanpa harus menggunakan uang tunai di puluhan ribu merchant yang bertanda DebitBCA di seluruh Indonesia. Adapun keuntungan berbelanja dengan debit BCA yaitu:lebih praktis karena tidak perlu membawa uang tunai untuk belanja, lebih mudah karena tidak perlu direpotkan dengan uang receh, lebih aman karena mengurangi resiko karena membawa uang banyak dan Kartu Paspor BCA dilindungi oleh PIN yang hanya diketahui oleh nasabah.

\section{c) Tunai BCA}

Sambil belanja sekalian tarik tunai lewat kartu paspor BCA, BCA menawarkan suatu bentuk kenyamanan dab kemudahan hidup bagi nasabah tabungan ( Tahapan BCA, Tapres) dan giro rupiah perorangan.selain berfungsi sebagai kartu ATM BCA, kartu paspor BCA juga dapat digunakan sebagai kartu Tunai untuk transaksi ambil tunai pada saat berbelanja di puluhan ribu merchant yang bertanda Tunai BCA di seluruh Indonesia.Keuntungan bagi nasabah menggunakan Tunai BCA yaitu: hemat waktu karena tidak perlu antri di bank atau di ATM, praktis dan nyaman karena sambil belanja bisa ambil uang tunai dan tanpa dikenakan biaya tambahan.

\section{d) Flazz BCA}

Merupakan alat pembayaran multifungsi tercepat pertama di Indonesia untuk kenyamanan bertransaksi. Menggunakan teknologi chip dan RFID (Radio Frequency Identification), kartu Flazz pantas untuk disebut sebagai kartu prabayar multifungsi dengan teknologi terkini, otorisasi transaksi pembayaran di chip di kartu Flazz itu sendiri. Pengisian ulang saldo (top up) pun mudah, cukup membawa Kartu Paspor ke ATM Non-Tunai BCA serta merchant-merchant berlogo Flazz isi ulang dan stand penjualan Flazz di mall terkemuka. Minimum top-up Rp 100.000 dan maksmum saldo yang dapat tersimpan dikartu maksimum Rp 1.000.000. kartu Flazz menawarkan kecepatan, kemudahan, kepraktisan bertransaksi. Cepat, karena transaksi pembayaran diselesaikan dalam hitungan detik. Mudah, karena tidak perlu menginput PIN. Praktis, karena tidak perlu menyimpan uang receh. Selain itu murah karena tanpa biaya transaksi. Kemudahan bagi merchant, tidak perlu sedia uang kembalian, mempercepat 
layanan karena tidak perlu mengecek keaslian uang dan menghitung uang saat bertransaksi, juga tidak perly menyimpan hbentuk fisik uang.

\section{e) BCA By Phohe}

Merupakan produk perbankan elektronik yang disediakan membantu nasabah untuk dapat menerima layanan iformasi perbankan dan melakukan transaksi finansial non tunai melalui pesawat telepon (touch tone atau handphone). BCA by phone merupakan layanan perbankan yang praktis karena nasabah dapat langsung melakuan transaksi perbankan melalui pesawat telepon tanpa harus datang ke bank atau ATM BCA, user Friendlykarena rekaman instruksi-instruksi yang mudah diikuti akan menuntun nasabah dalam melakukan berbagai transaksi perbankan, nyaman karena nasabah dapat langsung menuju layanan yang dikehendaki, tanpa harus menunggu dan mendengar semua instruksi selesai, dan aman karena BCA by phone dilengkapi dengan sistem keamanan berlaps, yaitu Personal Identification Number (PIN) dan KeyBCA. KeyBCA harus dipergunakan jika nasabah bertransaksi finansial seperti transfer antar rekening di BCA, pemayaran tagihan ataupun pmeblian pulsa isi ulang. KeyBCA, alat pngaman tambahan berfungsi menghasilkan password yang selalu berganti setiap kali nasabah melaukan transaksi finansial sehingga transaksi nasabah lebih aman.

\section{f) Mobile BCA (m-BCA)}

Dengan layanan ini nasabah serasa memiliki ATM BCA dalam genggaman tangan (kecuali untuk penarikan tunai). Berbagai transaksi perbankan dapat dilakukan nasabah melalui ponselnya, seperti semudah bertransaksi di ATM BCA. Transaksi yang dapat dilakukan dengan m-BCA yaitu: m-Info, m-Transfer, m-Payment, m-Commerce, dan m-Admin.

Keuntungan dan kenyamanan bertransaksi melalui m-BCA, merupakan layanan perbankan yang mudah, praktis, aman dan user friendly. Mudah, nasabah dapat bertransaksi dengan menu yang ada, dan tidak perlu memiliki keterampilan khusus untuk menggunakannya. Praktis, nasabah dapat langsung bertransaksi perbankan melaui ponsel kapan saja dan dimana saja. Aman, m-BCA dilengkapi dengan sistem proteksi yang maksimal. Selain menggunakan PIN yang dipilih sendiri dan nomor ponsel yang nasabah daftrakan, setiap transaksi yang dilakukan juga akan di encrypt (diacak) untuk menjamin keamanan transaksi nasabah. User friendly, menu m-BCA dirancang sedemikian rupa sehingga mudah diguakan oleh siapa saja. Nasabah perlu memilih jenis transaksi dari menu yang sudah tersedia, sehingga tidak perlu mengingat/menghafal kode transaksi yang ingin dilakukan. Nyaman, melaui m-BCA nasabah seperti memiliki TM BCA pribadi dalam genggaman tangan nasabah, karena berbagai transaksi yang dapat dilakukan di ATM BCA dapat dilakukan melalui m-BCA (kecuali penarikan tunai).

\section{g) SMS BCA}

SMS BCA adalah layanan informasi perbankan yang dapat diakses langsung oleh nasabah melalui telepon seluler atau handphone dengan menggunakan media SMS (Short Message Services). Keuntungan menggunakan SMS BCA yaitu begitu mudah untuk mendaftarkan nomor ponsel hanya perlu datang ke ATM BCA dimana saja, dan tidak perlu memiliki keterampilan khusus untuk menggunakannya. Dengan mengetik perintah (isi sms) dan mengirimkan ke 
nomor tertentu, maka jawaban akan diterima dalam bentuk sms yang dapat nasabah simpan dan telepon genggam nasabah. Dengan praktis, nasabah dapat memperoleh informasi perbankan langsung melalui ponsel kapan saja dan dimana saja. Apapun jenis ponsel nasabah, dapat menggunakan SMS BCA, tanpa perlu ganti SIM card dan nasabah akan nyaman melalui SMS BCA karena tidak perlu lagi mengantri di ATM, atau datang ke cabang BCA untuk sekedar cek saldo atau cek mutasi rekening.

\section{SIMPULAN}

Dari uraian di atas dapatlah di ambil kesimpulan tentang penerapan sistem informasi pada PT. Bank Central Asia Tbk (BCA) sebagai berikut:

1) Peranan sistem informasi bank memiliki peranan yang penting sebagai keberhasilan karena sebagai sistem penunjang operasi dan sebagai sistem penunjang manajemen.

2) Bank BCA memiliki produk yang ditawarkan kepada nasabah seperti produk simpanan, kartu kredit, fasilitas kredit, layanan transaksi perbankan, layanan cash management, fasilitas ekspor/impor, fasilitas valuta asing dan perbankan elektronik.

3) Perbankan elektronik yang dimiliki BCA adalah ATM BCA, debit BCA, tunai BCA, flazz BCA, BCA by phone, m-BCA, dan SMS BCA.

\section{DAFTAR PUSTAKA}

Abdul Kadir, 2003, Pengenalan Sistem Informasi, Andi, Yogyakarta.

Amsyah, 2005, Manajemen Sistem Informasi, Gramedia Pustaka Utama, Jakarta.

Azhar Susanto, 2007, Sistem Informasi Manajemen, Lingga Jaya,Bandung.

Azhar Susanto, 2008, Sistem Informasi Akuntansi, Lingga Jaya, Bandung.

G. Murdick Robert, dan E. Ross Joel, 1986, Sistem InformasiUtuk Manajemen Modern, Edisi ke-3, Erlangga, Jakarta.

Hadiwijaya, Wirasasmita R, 2000, Manajemen Dana Bank, Pioner Jaya, Bandung.

Husein M, Wibowo, 2002, Sistem Informasi Manajemen, AMP YKPN, Yogyakarta.

Leman, 1998, Metodologi Pengembangan Sistem Informasi, PT. Elex Media, Jakarta.

M. Scott, 2004, Prinsip-prinsp Sistem Informasi Manajemen, Rajagrafindo

Persada, Jakarta. 
UU No.10 Tahun 1998 Tentang Perubahan Atas UU No. 7 Tahun 1992 Tentang Perbankan

Raymond McLeod Jr, dan George P. Schell, 2004, Sistem InformasiManajemen, Edisi ke-8, PT. Indeks, Jakarta.

Raymond McLeod Jr, dan George P. Schell, 2007, Sistem Informasi Manajemen, Edisi ke-9, PT. Indeks, Jakarta.

Safitri, R. N., \& Marlius, D. (2017). Penerapan E-Banking Dalam Meningkatkan Jasa Dan Layanan Perbankan Di PT. Bank Rakyat Indonesia Cabang Padang. https://doi.org/10.31227/osf.io/gkv8t

Siagian, Sondang P, 2001, Sistem Informasi Manajemen, Bumi Aksara, Jakarta.

Sutarman, 2012, Pengantar Teknologi Informasi, Bumi Aksara, Jakarta

Susanto, R. (2018). Mekanisme Pelaksanaan Jasa Transfer Dalam Negeri Pada PT. Bank Pembangunan Daerah Sumatera Barat. https://doi.org/10.31227/osf.io/8uzs3

Zulkifli Amsyah, 2005, Manajemen Sistem Informasi, PT. GramediaPustaka Utama, Jakarta. 